\title{
O FUTEBOL NO ESPAÇO AUTOBIOGRÁFICO: UMA ANÁLISE DAS OBRAS DE NICK HORNBY
}

\section{FOOTBALL IN AN AUTOBIOGRAPHIC SPACE: AN ANALYSIS OF NICK HORNBY'S PRODUCTIONS}

\author{
Natasha Santos-Lise ${ }^{*}$
}

\section{RESUMO}

A presente pesquisa busca discutir o futebol, a partir de outras produções de Nick Hornby, como as coletâneas My Favourite Year (1993), Pray (2012) e Fan Mail (2013). Foram utilizados, também, alguns textos publicados no jornal The Independent, entre 1993 e 95. O objetivo foi identificar as rupturas e/ou continuidades à autobiografia Febre de Bola, seja com relação à forma de escrita ou com o conteúdo. Para tanto, buscou-se apoiar metodologicamente na perspectiva de texto e contexto, desenvolvida por Antonio Candido, bem como no conceito de "espaço autobiográfico", definido por Philippe Lejeune. Pode-se perceber que o tratamento do futebol, de acordo com a análise das obras de Hornby, passa por três significados distintos - memória, verossimilhança e notícia.

Palavras-chave: Literatura; Esporte; Futebol Inglês.

\begin{abstract}
The present research aims to discuss football, from Nick Hornby productions, such as the collections My Favorite Year (1993), Pray (2012) and Fan Mail (2013). Some texts published in The Independent between 1993 and 1995 were also used. The objective was to identify ruptures and / or continuities in autobiography Fever Pitch, whether in writing or in content. For this, we sought to support methodologically in the perspective of text and context, developed by Antonio Candido, as well as in the concept of "autobiographical space", defined by Philippe Lejeune. It can be seen that the treatment of football, according to the analysis of Hornby's works, has three distinct meanings: memory, verisimilitude and news.
\end{abstract}

Keywords: Literature; Sport; English football.

“Doutora em Educação Física. Universidade Federal do Paraná. E-mail: natashaslise@gmail.com. 


\section{INTRODUÇÃO}

Meu primeiro livro vendeu razoavelmente bem; por outro lado, os livros que adorei e sobre os quais escrevi resenhas em 1991 e 1992, tão bons ou melhores do que o meu, já saíram de circulação, simplesmente porque nunca atraíram um número razoável de leitores (HORNBY, 2009, p. 56 fevereiro de 2004).

Muito embora o texto autobiográfico assuma, em partes, o caráter inventivo, uma vez que estaria intimamente vinculado a construções artificiais, já que narrador e personagem tendem a se confundir na narrativa, não se pode negligenciar a questão da memória (ALBERTI, 1991; CALADO, 2009; SANTOS, 2006). Ou seja, o autor pretende que sua narrativa seja tratada enquanto um texto verídico, sincero e autêntico, todavia, esta intenção não garanta o rompimento com a subjetividade do escritor, ao omitir acontecimentos de sua vida ou transformálos segundo a conveniência de sua perspectiva. Esse julgamento com base na intenção de verdade é o que aproxima a autobiografia da história, ao mesmo tempo em que há a impossibilidade de se alcançar uma essência verdadeira. Começa-se, aqui, a delinear um gênero híbrido que, apesar da tentativa de verdade, atinge acepções também literárias.

O crítico inglês Raymond Williams (2014), ao se debruçar sobre o entrelaçamento entre literatura e sociedade, expõe que o processo de produção da escrita é também social e acontece junto à construção de aspectos estéticos no texto. Dessa forma, embora os elementos sociais contribuam significativamente para a produção da literatura, não se pode dizer que esses elementos contextuais estejam puros, sem qualquer deformação, ao longo da obra.

Nesse mesmo sentido, ao se referir ao elemento sociológico (externo), Candido (2014) aponta que este é importante na medida em que desempenha um papel na constituição da estrutura da obra - tornandose, portanto, um elemento interno ao texto. Tal constatação dialoga com a percepção de Williams ao tratar do bucólico nas produções inglesas seiscentistas, por exemplo, quando percebe a mudança do estilo de escrita, atrelada às mudanças na paisagem campestre.

Ao tratar dos aspectos que colocam a autobiografia como um gênero de referência, Philippe Lejeune (2014) aponta, também, para o elemento autobiográfico que pode existir em gêneros de ficção, como o romance. Dessa forma, os textos que, embora sejam narrativas sobre a vida de determinado personagem, não se declarem como autobiografias, são tratados por Lejeune (2014, p. 29) como romances, os quais podem até ser autobiográficos: "Chamo assim (romances autobiográficos) todos os textos de ficção em que o leitor pode ter razões de suspeitar, a partir das semelhanças que acredita ver, que haja identidade entre autor e personagem, mas que o autor escolhe negar essa identidade ou, pelo menos, não afirmála". Nesse sentido, é possível pensar em um "espaço autobiográfico", composto pelas obras do escritor em um sentido mais amplo, com o intuito de refletir sobre estilos de escrita e mesmo elementos da vida do escritor.

A presente pesquisa se refere, assim, a uma parte da pesquisa de doutorado, relacionada à análise do futebol na obra autobiográfica do autor inglês Nick Hornby, intitulada Febre de Bola (1992). Pretende-se tratar, aqui, portanto, das obras sobre futebol, além da autobiografia, produzidas por Nick Hornby. Após Febre de Bola, sua primeira publicação literária, em 1992, o escritor dedicou muitos livros ao esporte e, naqueles em que não trata do futebol, este aparece entre um diálogo e outro.

Entre as produções esportivas, pode-se citar quatro obras:

1) My Favourite Year, publicado em 1993, que se refere a uma coletânea de escritos sobre o futebol, em que Hornby organiza textos de outros autores. Um dos capítulos é de sua autoria - The Abbey Habit -, e está disponível no livro Fan Mail.

2) The Picador Book of Sportswriting, publicado em 1997, também é uma coletânea editada por Nick Hornby e Nick Coleman.

3) Pray: Notes on the 2011/2012 Football, 2012, não-ficção, coletânea de textos de futebol, sobre a temporada em questão.

4) Fan Mail: twenty years of writing about soccer, 2013, não-ficção, coletânea de textos de futebol, escritos ao longo de 20 anos e publicados em jornais, revistas e livros. Inclusive, Pray é um dos textos organizados nesta edição. 


\section{UM ESPAÇO AUTOBIOGRÁFICO}

Pray e Fan Mail foram publicados apenas no formato de $e$-book, pela Penguin Specials ${ }^{1}$. Ambos se aproximam da ideia de Febre de Bola, com crônica, seguida da data e das equipes que jogaram. Sobre My Favourite Year, o jornal The Observer, publicou a seguinte matéria:

Uma "coleção da nova escrita do futebol" está sendo publicada, na qual os literatos tentam resgatar a reputação do jogo. [...]. A coleção, My Favorite Year, é editada por Nick Hornby, o homem que acertou o chute na gaveta das publicações com seu livro Febre de Bola, detalhando sua devoção ao Arsenal. My Favourite Year marca o surgimento de uma nova classe de torcedores de futebol - culta, discernida e amplamente lida (WROE, 31 out. 1993, p. 6). ${ }^{2}$

Na sequência, no The Observer do dia 07 de novembro de 1993, foi publicado um trecho de $M y$ Favourite Year, ocupando três páginas. O excerto supracitado aponta para o surgimento de uma nova escrita do futebol, bem como de uma nova classe de torcedores, que seriam cultos. Cabe lembrar que Febre de Bola se refere ao espectador de futebol, sim. E, conforme já apontado por Lise (2018), uma releitura em contrapartida ao torcedor desregrado, sobre o qual tanto se falou ao longo da década de 1980 e início de 90. Jeffrey Hill (2006) reitera tal perspectiva, ao afirmar que Hornby, de certa, forma, reabilita a imagem do torcedor, ao representa-lo como uma pessoa comum - talvez mais obsessiva. Dessa forma, concorda-se com Martin Wroe (31 out. 1993, p. 6.), sobre uma tentativa - exposta sobretudo em Febre de Bola - de resgatar a reputação do jogo que, como exposto mais adiante, é um dos pontos de maior reverberação e elevação da autobiografia em foco.

Todavia, é problemática a assertiva de Wroe, ao dizer que, junto a esta nova literatura que se estabelecia, surgia um novo tipo de torcedor, que se dedicaria à

\footnotetext{
${ }^{1}$ A Penguin Specials, uma variação da marca Penguin Books, se dedica à publicação de livros de leitura rápida, de autores contemporâneos, com versão em e-book apenas. Nick Hornby possui três publicações neste formato - além de Pray (2012) e Fan Mail (2013), há Books, Movies, Rythm and Blues (2013). ${ }^{2}$ Originalmente: "A 'collection of new football writing' is being published in which the literati attempt to rescue the game's reputation. [...] The collection, My Favourite Year, is edited by Nick Hornby, the man who kicked football into publishing's top drawer with his book Fever Pitch, detailing his lifelong devotion to Arsenal. My Favourite Year marks the emergence of a new class of football fan - cultured, discerning and widely-read" (WROE, 31 out. 1993, p. 6).
}

leitura. Embora o foco da matéria seja My Favorite Year, é importante lembrar que, em Febre de Bola, Nick Hornby busca, exatamente, mostrar que, antes da publicação de sua autobiografia, já existiam torcedores cultos, sendo ele próprio um destes. O meio pelo qual o literato busca resgatar determinada honra do esporte é falando de si mesmo, enquanto um dos torcedores que não se encaixava no estereótipo de violência. Dessa forma, essa nova literatura pode ter levado o futebol a indivíduos cultos, que não acompanhavam o esporte; mas é pouco plausível dizer que esses indivíduos se tornaram torcedores. As mudanças nos estádios, relacionadas à espetacularização, certamente mudaram, de forma lenta e gradual, as formas de torcer e de consumir o esporte, entretanto, é complexo afirmar que essas novas maneiras atingiram torcedores mais ou menos cultos.

Embora tenha aparentemente produzido pouco sobre futebol - já que muito se fala de Febre de Bola, apenas -, Hornby se tornou colunista em algumas revistas e jornais como Time Out e Times Literary Supplement, em adição a suas análises musicais para o New Yorker. Além de escrever sobre futebol em The Sunday Times, algumas contribuições esportivas foram publicadas por The Guardian e The Independent, assim como no site da ESPN.

Na introdução ao livro Fan Mail, Nick Hornby apresenta uma justificativa a respeito de sua produção literária do futebol: "Eu tinha medo de que meu primeiro livro, Febre de Bola, que descreve meu relacionamento com o Arsenal FC (embora, se você tiver chegado a ler isto, você bem sabe disso) poderia me estereotipar, e é por isso que eu nunca escrevi outro livro completo sobre o assunto" (HORNBY, 2013, $\mathrm{s} / \mathrm{p})^{3,4}$. Todavia, Febre de Bola sempre aparece como uma grande referência. Seja em sites relacionados a esporte, como o da ESPN, em que a apresentação de Hornby é feita da seguinte forma: "Nota dos editores: [...] Nick Hornby - romancista e roteirista que escreveu sobre sua obsessão como torcedor do Arsenal

\footnotetext{
${ }^{3}$ Originalmente: "I had been afraid that my first book, Fever Pitch, which describes my relationship with Arsenal FC (although if you've got as far as reading this, you may well know that already) might stereotype me, which is why I never wrote another full-length book on the subject" (HORNBY, 2013, s/p).

${ }^{4}$ É importante destacar que, por se tratar de um e-book, este não possui páginas, mas "posições", que podem variar de acordo com o dispositivo em que se está lendo. Neste caso, usando como referência o Kindle, com tamanho de letra 5, tal citação se encontra na posição 43 do livro.
} 
em Febre de Bola" (ESPN, 15 jun. 2017) ${ }^{5,6}$. Ou nas entrevistas, disponíveis no YouTube, em que o assunto não é o esporte, propriamente (YOUTUBE, 2015, 2016). Em todas essas menções, entretanto, a ênfase não parece ser apenas no fato de ser um entendedor do esporte, como se pode supor acerca da ESPN, mas o que é destacado é, também, a grandiosidade da obra, visto que foi o livro que o tornou conhecido. Dificilmente, a autobiografia deixe de ser considerada a sua maior obra - ao lado de Alta Fidelidade.

Coadunando-se ao incômodo de ser visto como um autor de esportes, Nick Hornby compara sua imagem nos Estados Unidos e no Reino Unido... "É interessante, porque em alguns aspectos, eu prefiro minha carreira norte-americana do que minha carreira britânica. Tudo no Reino Unido é visto pelo prisma do meu primeiro livro, Febre de Bola, e porque eu escrevi sobre futebol, então é isso, eu era um escritor do futebol" (YOUTUBE, 10 fev. 2015). Esta comparação, inclusive, é recorrente em Stuff I've been Reading, especialmente ao alegar que os norteamericanos são mais abertos a novos tipos de arte. No caso desta entrevista, Hornby se vê como mais eclético nos EUA, considerando as obras publicadas e filmes lançados no país. O que Hornby parece desconsiderar é a pouca popularidade do soccer nos Estados Unidos, algo que poderia contribuir para a menor retomada da autobiografia pelos americanos - embora, na mesma entrevista de que foi retirada a fala supracitada, a qual foi realizada em solo americano, para o Google Talks, o escritor é questionado sobre Febre de Bola. Isso leva a crer que a diferença entre EUA e Reino Unido possa estar na discussão sobre arte, no sentido de definir o que é clássico e o que não é, por exemplo.

Esse afastamento do futebol, somado a essas declarações que levam a crer que Nick Hornby não quer ser visto como um autor esportivo, são, de certa forma, surpreendentes, dado todo o seu envolvimento afetivo com o Arsenal. Todavia, Hornby não deixou

\footnotetext{
${ }^{5}$ Disponível em: <http://www.espn.com/soccer/club/arsenal/359/blog/ post/3143118/nick-hornby-on-arsenal-and-arsene-wenger-after-horriblepremier-league-campaign $>$.

${ }^{6}$ Originalmente: "Editors' note: [...] Nick Hornby - novelist and screenwriter who wrote about his obsessive fandom of Arsenal in "Fever Pitch"' (ESPN, 15 jun. 2017).

${ }^{7}$ Transcrição livre. Originalmente: "It is interesting, because in some ways I prefer my American career to my British career. Everything in UK is seen through the prism of my first book, which is Fever Pitch, and because I wrote there about football, then that was it, I was a football writer. Forever" (YOUTUBE, 10 fev. 2015).
}

exatamente de escrever sobre o esporte, pois se tornou colunista do Sunday Times ${ }^{8}$, chegando a publicar alguns textos no Guardian. Junto a isso, há a introdução de Febre de Bola, escrita 20 anos depois de sua primeira publicação (HORNBY, 2013, p. 9-15), em que Hornby, cuidadosamente, trata da prerrogativa de que livros de futebol não vendem, sendo este o motivo pelo qual a autobiografia foi recusada à publicação algumas vezes. Além disso, o autor destaca as reapropriações da obra, segundo as quais, esta teria vendido o esporte para a classe média, o que Hornby retoma em algumas de suas falas, ao alegar, por exemplo, que as pessoas (sem especificar quem) levaram o livro a sério demais, quando o que o escritor fez, na realidade, teria sido algo simples (YOUTUBE, 10 fev. 2015).

É possível que Nick Hornby quisesse se dedicar ao romance e aos roteiros, já que, antes de emplacar Febre de Bola, suas tentativas consistiam em roteiros para a TV (YOUTUBE, 10 fev. 2015), sendo todos recusados...

Comecei escrevendo peças [...] e elas não eram muito boas... quando eu saí da universidade e tentei escrever, tudo soou como ensaios ruins, então pensei que deveria manter o diálogo. Eu não tinha feito leitura suficiente - não das coisas que eu queria imitar - então demorei um tempo, um longo tempo, para lidar com a voz ... tudo mudou para mim quando eu li Anne Tyler, Raymond Carver, Richard Ford e Lorrie Moore, tudo em torno de 1986-87... voz, tom, simplicidade, humor, alma... todas essas coisas pareciam estar perdidas na ficção inglesa contemporânea que eu olhava, e eu sabia o que queria fazer (NICK HORNBY, 2017, s/p). ${ }^{9,10}$

A inspiração em Anne Tyler é retomada em Frenesi Polissilábico:

\footnotetext{
${ }^{8}$ Não foi possível o acesso a tais produções, uma vez que, embora a autora seja assinante do jornal The Times, os arquivos digitais disponibilizados, abrangem dois séculos de publicações, todavia o período é de 1785 a 1985. Não há o intervalo específico de tempo em que Hornby escreveu para o Sunday Times, mas começou na década de 1990, após a publicação de Febre de Bola. Para ter acesso a tal conteúdo, apenas via bibliotecas britânicas.

${ }^{9}$ Originalmente: "I started by writing plays [...] and they weren't very good... When I left university and I tried to write, everything came out sounding like bad essays, so I thought I should stick to dialogue. I hadn't done enough reading - not of the things I wanted to emulate - so it took me a while, a long while, to grapple with voice... everything changed for me when I read Anne Tyler, Raymond Carver, Richard Ford, and Lorrie Moore, all in about '86-'87... voice, tone, simplicity, humour, soul... all of these things seemed to be missing from the contemporary English fiction I'd looked at, and I knew then what I wanted to do"' (NICK HORNBY, 2017, s/p).

${ }^{10}$ Disponível em: <https://www.nickhornbyofficial.com/about/>.
} 
Quando comecei a escrever pra valer, li Almoço no restaurante da saudade, de Anne Tyler, e de repente fiquei sabendo o que era o que queria ser, para o bem e para o mal. [...] cada decisão artística, cada impulso, a alma do trabalho bem como a de seu criador. "Isso sou eu", foi o que tive vontade de dizer ao ler o suntuoso, triste e adorável romance de Tyler (HORNBY, 2005, p. 16-17).

A referida obra de Tyler - que, como dito previamente, conta com um desmaio no estádio de beisebol bastante parecido ao descrito por Hornby na autobiografia -, se refere a um drama familiar, em torno de uma mãe e seus três filhos. Pearl Tull tinha já idade avançada quando se casou com Beck Tull. Tiveram três filhos: Cody, Ezra e Jenny. A história, de narrador onisciente, tem início com a mãe doente, em 1979. Os flashbacks são, assim, um recurso comum na obra em questão, no sentido de contar a história da família, bem como de construir psicologicamente o perfil de cada personagem. Beck, que passava boa parte das semanas viajando a trabalho, abandonou a família em 1944, quando os filhos tinham, respectivamente, 14, 11 e 9 anos de idade. Essa informação, junto à idade posterior dos personagens (por exemplo, Ezra aos 46 anos cuidando da mãe), é o que permite ao leitor se localizar temporalmente.

Pois bem, se para os filhos, principalmente Cody, a mãe era muito dura; esta enfrentava a árdua tarefa de criar três filhos sozinha. Embora o exmarido enviasse quantias em alguns meses, Pearl começou a trabalhar no caixa de uma mercearia, para complementar a renda. Isso tornou ainda mais difícil a tarefa, já que passava boa parte do dia fora. Tem-se, por um lado, uma mãe preocupada, que acaba por se abster de afetividade para com os filhos; e, por outro, filhos carentes disso.

As refeições são enfatizadas ao longo da narrativa, pois, o "Restaurante da Saudade" é de propriedade de Ezra e a refeição traz a significação de carinho - uma falta naquela casa, já que nunca conseguiram terminar um só jantar sem brigas. Além disso, ao longo da infância dos filhos, as discussões aconteciam na hora das refeições - mesmo porque, era o momento em que todos estavam reunidos. Paralelamente, Ezra sempre teve a habilidade de apresentar comida a quem estivesse triste, como uma forma afetuosa de consolo.
Anne Tyler trata de uma família fora dos padrões, que carrega uma série de diferenças e dificuldades de relacionamento. Todavia, é uma família com os mesmos problemas de qualquer outra, e essa percepção é recorrente nas obras de Hornby, como Slam, Um Grande Garoto e Como ser legal. Dessa forma, ao dizer "isso sou eu", a respeito do romance em questão, é como se o autor estivesse se amparando em narrativas a respeito de filhos que, como ele próprio, deram certo na vida, apesar de terem os pais separados.

A linguagem simples e compreensível convergente à escrita de Tyler - junto ao humor majoritariamente autodepreciativo, apareceu aos montes em Febre de Bola, o que facilitou a transcendência da obra ao âmbito esportivo. É possível que o autor intentasse voar pelos campos da ficção, como os escritores que lhe inspiraram, os quais não se dedicavam tanto ao esporte - à exceção de Frederick Exley e sua proximidade ao futebol americano. Ou há a possibilidade de o fanatismo de que Nick Hornby trata na autobiografia ter esmaecido, seja por conta do tempo disponível ou por uma simples mudança de prioridades. Uma terceira possibilidade pode estar relacionada ao fato de que a autobiografia foi encarada como uma espécie de propaganda do futebol à classe média, quando o objetivo de Hornby parecia ser, exatamente, o oposto - mostrar o quanto a febre de bola era inviável ao consumo do futebol. O estudioso Jeffrey Hill (2006) destaca algo nesse sentido: o que escritor detestaria é o modo com que o futebol foi apropriado pela classe média, sendo Febre de Bola culpado por isso, em partes. Outra coisa já elencada por Antony King (2002) é que Hornby, embora se visse como pertencente ao grupo de torcedores de classe baixa, ele pertencia, já na década de 1970, à classe média. Por esse motivo, essa aversão a uma reformulação do esporte se apresenta como um relativo paradoxo, se vista do ponto de vista de classe. Apesar de o foco das mudanças estar em atingir a classe média, Nick Hornby não manifestou, efetivamente, qualquer crítica a determinado estrato social, mas às formas de torcer, que não seriam as mesmas. Supostamente, não haveria a febre de bola entre os novos torcedores.

Ainda na introdução do livro, escrita em 2012, Hornby aponta, como já mencionado em capítulos anteriores, que não seria capaz de escrever Febre de 
Bola naquele momento, destacando o fato de que sua perspectiva mudou em relação ao personagem da autobiografia (HORNBY, 2013, p. 15). E, dramaticamente, registra que sente falta daquela pessoa que "[...] tinha tempo e energia para tanta angústia e paixão, e, se fosse escrever sobre ele agora, provavelmente lhe faria um afago na cabeça e contaria que, quando ele fosse mais velho e mais sábio, a própria razão da existência deste livro (Febre de Bola) teria se perdido" (HORNBY, 2013, p. 15). Nick Hornby escreve como alguém que sofreu uma enorme decepção, possivelmente se referindo às mudanças nos estádios que, consequentemente, transformaram as formas de torcer. O futebol, em si, se transformou, o que acentua ainda mais o saudosismo já presente em 1992. E, além disso, há a possibilidade de que a autobiografia, como sugere o autor, tenha sido reapropriada para promover o consumo do futebol exatamente aquilo a que Hornby critica.

\section{A OBRAS DE FICÇÃO}

É importante ressaltar, também, que o esporte jamais deixou de aparecer em seus textos, como nas colunas da Believer, nas quais, como visto no capítulo anterior, o futebol figura como o motivo dos atrasos nas leituras - o que acaba se delineando como um elemento de humor no texto. Já na ficção, a modalidade se estabelece como um dos efeitos de verossimilhança, que auxiliam na compreensão de que a história narrada é possível.

Em Como ser legal (2002), por exemplo, quando David e Karen conversam sobre dar abrigo a um morador de rua, o marido acusa a esposa de ter uma visão estereotipada daqueles. Karen responde:

- Sei muito bem o que estou fazendo, David. Mas sabe... o estereótipo do torcedor de futebol é alguém que se embebeda e quebra garrafas nas cabeças das pessoas. Sei que isso é um estereótipo e conheço muitos torcedores do Arsenal que não são assim. Mas... talvez haja alguns que realmente são. E acho que não quero dizer à Ros e ao $\operatorname{Max}^{11}$ que eles precisam morar com esse pessoal (HORNBY, 2002, p. 151).
Aqui, o esporte é completamente acessório na narrativa, mas permite que o diálogo seja reconhecido como cotidiano, banal. E é possível perceber que Nick Hornby traz parte da discussão implícita em Febre de Bola, sobre a marginalização dos torcedores de futebol, especialmente, após os desastres nos estádios.

Em Uma longa queda (2014), Maureen tem um filho deficiente, em estado vegetativo, e ela tenta decorar o quarto com coisas que um menino da idade dele possivelmente gostaria. Entre essas coisas, estava um pôster de Paddy, jogador do Arsenal... "O John é um homem gentil, e comprou uma foto enorme e muito boa do Paddy comemorando um gol, e nem quis que eu pagasse [...]. Por alguma razão, ele achou que meu menino era um menino pequeno, de dez ou doze anos, e prometeu leva-lo a um jogo" (HORNBY, 2014, p. 155).

Ou, ainda, em Funny Girl (2014), como um recurso para elucidar a má situação de um dos atores... "Clive sentia como se, numa partida de futebol, tivesse tomado três gols nos dois primeiros minutos de jogo, e embora suspeitasse que agora até um empate estava fora do alcance, podia pelo menos fazer o gol de honra" (HORNBY, 2014, p. 84) ${ }^{12}$. Clive era o ator da série cômica Barbara (e Jim) e estava perdendo espaço para Sophie Straw, que interpretava Barbara - personagem de destaque.

Por fim, Nick Hornby escreveu um conto, no livro infanto-juvenil Foras da lei barulhentos, bolhas raivosas e algumas outras (2012). No texto, Pequeno País, a história gira em torno de Stefan, um menino que detesta futebol, mas que é obrigado a substituir o pai, que quebrou a perna, na seleção. Contando com pai de Stefan, são 11 os homens e meninos de Champina, em condições de correr. Ou seja, todos eles compõem a seleção, capaz de perder para San Marino, por um placar de 30 a 0 . Acaba que no dia do jogo, taticamente, Stefan, com as estratégias de um jogador de xadrez, ajuda a equipe, que perde por 16 a 0 - sendo o mais impressionante o fato de ter levado apenas 3 gols no segundo tempo. Novamente, Hornby traz a intelectualidade para o esporte, ao permitir, literariamente, que um personagem que é

\footnotetext{
${ }^{12}$ Originalmente: "Clive felt as though he'd gone three goals down in the first two minutes of a football match, and though he now suspected that even a draw was beyond him, he could at least make a better fist of things" (HORNBY, 2014, p. 84).
}

${ }^{11}$ Ros e Max são vizinhos de Karen e David, que abrigaram um morador de
rua. O menino fugiu levando alguns pertences do casal. 
um estudioso e que está longe de ser um atleta possa ajudar um time a vencer uma partida de futebol.

Com base nesses exemplos, fica evidente que o esporte não ocupa centralidade da ficção de Nick Hornby. Apesar de o futebol assumir o papel de verossimilhança, como apontado anteriormente, devese ressaltar que os romances de Hornby se aproximam da literatura pop e, portanto, o assunto da narrativa é o cotidiano, o que por si só, torna a história possível de acontecer. Todavia, embora não tenha papel preponderante, a modalidade reforça a banalidade (não tão banal) das obras, tendo em vista que, facilita a identificação com o diálogo dos personagens.

\section{AS OBRAS DE NÃO-FICÇÃO}

Todos esses elementos mudam de figura, quando se trata de Fan Mail (2013) e Pray (2012), mesmo porque se referem a textos não-ficcionais.

Seguindo um formato parecido ao de Febre de Bola, Pray traz as datas e os placares dos jogos, todavia, a vida de Nick Hornby já não aparece atrelada ao futebol e a centralidade não é do Arsenal nem do torcedor. O que se tem no livro é uma escrita essencialmente voltada à temporada de 2011/12, cujo início demonstrava o abismo econômico entre os clubes.

Nem sempre foram os clubes maiores e mais ricos que terminaram campeões. Sete equipes diferentes chegaram ao topo da Primeira Divisão nos vinte anos anteriores ao início da Premier League em 1992: Aston Villa [...], Derby County, Nottingham Forest, Arsenal, Leeds United, Everton e, por onze vezes, Liverpool - que não era mais rico do que qualquer outro, era apenas melhor e mais inteligente e mais trabalhador (HORNBY, 2012, s/p). ${ }^{13} 14$

Tal como apontado anteriormente, o estabelecimento da Premier League, que começou efetivamente em 1992, fez emergir a forma de jogo contemporânea (KING, 2002; GOLDBLATT, 2015), algo já destacado por alguns pesquisadores e que é

\footnotetext{
${ }^{13}$ De acordo com o dispositivo Kindle, com letra tamanho 6, tal citação se encontra na posição 47.

${ }^{14}$ Originalmente: "It hasn't always been the biggest and richest clubs who finish champions. Seven different teams came top of the First Division in the twenty years before the Premiership began in 1992: Aston Villa [...], Derby County, Nottingham Forest, Arsenal, Leeds United, Everton, and, eleven times, Liverpool - who weren't richer than any of the others, just better and smarter and more industrious" (HORNBY, 2012, s/p).
}

retomado por Hornby. Assim, com a entrada do dinheiro da televisão e a liberdade dos jogadores poderem sair do país, por exemplo, acentuou a lacuna entre os clubes grandes e pequenos, já que, como destaca David Goldblatt (2015), há uma íntima relação entre o salário dos jogadores e as vitórias da equipe.

Nick Hornby critica os investimentos bilionários dos compradores de alguns clubes, como o Chelsea de Roman Abramovich ou o Manchester City, do Grupo Abu Dhabi United. O escritor, em confluência com o pesquisador Goldblatt, aponta os resultados como uma "lição clara", já que havendo um industrialista ou um oligarca, o clube será rico e, consequentemente, ganhará títulos.

O que se buscou implantar nos clubes ingleses, já nos fins da década de 1980 e início da década de 1990, era um novo tipo de administração, pautada no modelo empresarial, o que exigia, inclusive, dirigentes com experiência em gestão... "Os clubes ingleses de futebol não foram incorporados a grandes empresas capitalistas. Em vez disso, os novos diretores apenas adicionaram o clube de futebol aos seus interesses de capital ou colocaram todo - ou uma parte substancial de - o seu capital em um único clube"15 (KING, 2002, p. 121). A princípio, como disserta o pesquisador, o objetivo era que o clube de futebol se transformasse em um negócio independente e rentável. É esta a lógica empresarial: um investimento que retorna lucrativamente ao investidor - no caso, o dirigente. A perspectiva relacional entre investimento e lucro, por si só, já seria suficiente para criar um abismo entre os clubes maiores e os menores; o que se soma, ainda, aos recursos advindos da televisão que, por óbvio, se concentrariam em maior escala nos clubes de maior torcida. Ou seja, seria um processo análogo à osmose, já que os investimentos se convergiriam para os times com maior potencial de propiciarem um retorno mais lucrativo.

Todavia, tal como aponta Goldblatt (2015), essa lógica empresarial não funcionou exatamente bem, haja vista o surgimento de indivíduos ou grupos bilionários - como Abramovich e Abu Dabhi -, que efetivam investimentos altíssimos e não obtêm lucro. Isso rompe com a estratégia de investir para

\footnotetext{
${ }^{15}$ Originalmente: "English football clubs have not been incorporated into larger capitalist companies. Rather, the new directors have merely added the football club to their capital interests or have put all - or a substancial part of - their capital in a single club" (KING, 2002, p. 121).
} 
obter lucro de qualquer empresa comum, tornandose catastrófico, competitivamente falando, para os clubes que não dispõem desta mina de ouro - que, por vezes, pode estar atrelada à lavagem de dinheiro. Daí a perspectiva de Nick Hornby, ao apontar os sheiks ${ }^{16}$ como a solução para que o clube consiga atingir a marca de seis vitórias e um empate, ao longo de três semanas de campeonato, por exemplo. Já que, podendo pagar os maiores salários, os clubes são capazes de formar um elenco capaz de vencer a Copa do Mundo, com os melhores jogadores de cada país. Dessa forma, Nick Hornby (2012) destaca que o Arsenal conseguiu vencer a Premier League por três vezes, sem ajuda financeira externa - o que é um grande feito, visto que o Manchester City, naquele momento, possuía recursos para bancar o dobro do valor máximo salarial que o Arsenal poderia assegurar. Muito embora sendo inebriado por um comportamento febril, Hornby negligencia que o Arsenal não é um clube de poucos investidores e sequer menciona a construção do novo estádio, com rights name da Emirates, por exemplo. Efetivamente - e esta tem sido uma discussão cada vez mais forte sobre os rumos da Premier League, em programas como o Futebol no Mundo, da ESPN -, o Arsenal não apresenta os mesmos recursos que Manchester City e Chelsea, mas, via de regra, se mantém entre os primeiros da tabela. Novamente, Hornby expõe um pensamento semelhante com o de Febre de Bola, quando reclama que o clube ficou por 17 temporadas sem ganhar um campeonato. Como se a febre de bola dependesse de títulos.

Diante dessa dificuldade para manter jogadores, Hornby destaca a amarga derrota para o Manchester United, pelo placar de 8 a $2 \ldots$
A catástrofe do Arsenal em Old Trafford, no entanto, a pior derrota da minha vida - a pior derrota nas vidas de qualquer torcedor do Arsenal com menos de 115 anos - só poderia ser parcialmente explicada pelo dinheiro e pelos jogadores que perderam, um dos quais foi seu capitão e um dos melhores jogadores do mundo, Cesc Fabregas (HORNBY, 2012, s/p). ${ }^{17} 18$

\footnotetext{
$\overline{{ }^{16} \text { No sentido ocidental da }}$ palavra, referindo-se àquele que possui posses.

${ }^{17}$ De acordo com o dispositivo Kindle, com letra tamanho 6, tal citação se encontra na posição 66.

${ }^{18}$ Originalmente: "Arsenal's catastrophe at Old Trafford, however, the worst defeat of my lifetime - the worst defeat in the lifetimes of any Arsenal fan under the age of 115 - could only partly be explained by money, and by the players they had lost, one of whom was their captain and one of the world's
}

Ora, no conto sobre o País Pequeno (HORNBY, 2012, p. 36), os personagens reconhecem que perder o segundo tempo, para San Marino, de apenas 3 a 0 foi o melhor resultado internacional de Champina. E imaginavam que, se jogassem daquele jeito em todo o tempo regulamentar, perderiam de 6 a $0 \ldots$ "Seis a zero parecia um placar de futebol. Times bons, times dos quais você ouvia falar, perdem por $6 \times 0$ às vezes. Ninguém nunca perde de $26 \times 0$, porém". Corroborando com a ficção, o Arsenal era um time grande de quem se ouvia falar e perdeu de $8 \times 2$.

Nick Hornby faz uma análise técnica do jogo, apontando o quanto os jogadores do Arsenal não tinham chances de levar menos do que cinco gols. Ou seja, “[...] A história da temporada, então, em uma única tarde: quem tem mais dinheiro vence, sem dúvida. Sheikh Mansoor venceu a Premier League, e Roman Abramovich venceu a Liga dos Campeões"19 ${ }^{20}$ (HORNBY, 2012, s/p). E, dessa forma, o futebol aparece como um grande meio de entretenimento e o grande inimigo de Hornby já não são os torcedoresconsumidores, que abandonariam o time em momentos de maus resultados, mas os grandes investidores dos clubes rivais.

Seguindo adiante na temporada, Hornby destaca dois casos de racismo, acontecidos em outubro de 2011. "Esses incidentes eram banais, feios e notavelmente semelhantes: dois jogadores bem conhecidos disseram o que não deveriam ter dito a oponentes negros" (HORNBY, 2012, s/p) 21 22. Nick Hornby se refere aos casos de Luis Suárez (Livrepool)/Patrice Evra (Manchester United); e John Terry (Chelsea)/ Anton Ferdinand (Queens Park Rangers). O autor abre, inclusive, uma breve discussão sobre a ética do esporte, haja vista que, embora outros torcedores ingleses, que não do Liverpool, admirem Suárez como jogador, certamente mantêm algumas ressalvas sobre as suas qualidades enquanto ser humano. Para além

\footnotetext{
best players, Cesc Fabregas" (HORNBY, 2012, s/p).

${ }^{19}$ Originalmente: “[...] The story if the season, then, in a single afternoon: the big money wins, emphatically. Sheikh Mansoor won the Premier League, and Roman Abramovich won the European Champions League" (HORNBY, 2012, s/p).

${ }^{20}$ De acordo com o dispositivo Kindle, com letra tamanho 6, tal citação se encontra na posição 79 .

${ }^{21}$ De acordo com o dispositivo Kindle, com letra tamanho 6, tal citação se encontra na posição 100 .

${ }^{22}$ Originalmente: “These incidentes were banal and ugly and remarkably similar: two well-known players said something they shouldn't have said to black opponents" (HORNBY, 2012, s/p).
} 
do racismo, que já seria, por si só, suficiente para tais restrições, houve a situação na Copa de 2010, em que ele impediu o gol da seleção de Gana com a mão, dentro da grande área. O jogador foi expulso e, quando o goleiro uruguaio defendeu o pênalti, as câmeras mostraram Suárez fora de campo, vibrando, como se tivesse marcado gol ${ }^{23}$.

Ou seja, ao longo desses textos referentes à temporada 2011/12, o escritor rompe com a literariedade dramática presente em Febre de Bola, passando a escrever sobre as quatro linhas em si. O estilo, a linguagem simples e o formato de boletim esportivo são o que permanecem no texto. Diferentemente de Fan Mail (2013), que traz textos mais semelhantes ao Febre de Bola, inclusive revisitando o best-seller. A coletânea se refere, como sugere o próprio subtítulo, a 20 anos de escrita sobre o futebol. Dessa forma, tudo já foi publicado antes e é mais uma mostra de que Hornby não deixou, efetivamente, de escrever sobre futebol, mas o retirou do cerne de sua produção literária, alegando que todas essas publicações foram propostas tentadoras.

The Abbey Habit: Cambridge United 1983/84 abre a coletânea. O texto foi publicado pela primeira vez no livro de organização de Nick Hornby, $M y$ Favourite Year, de 1993. O Cambridge United, cujo estádio se chama Abbey, é um velho conhecido em Febre de Bola. Na autobiografia, Hornby dedica alguns textos a tratar dos jogos do time, que passou a acompanhar quando entrou na universidade. Dessa forma, pode-se dizer que o literato torcia para outra equipe, sendo esta mais modesta. $\mathrm{Na}$ temporada de 1983/84, o Cambridge United venceu apenas quatro jogos e perdeu 24. Foi uma temporada terrível, que culminou com o rebaixamento da equipe que, mais tarde, retornaria à quarta divisão.

Assim como em Febre de Bola, Nick Hornby traz assuntos pessoais para o texto. Ao se questionar, por exemplo, se existe algo como uma personalidade propensa ao vício, o autor conta que está tentando parar de fumar e compara o cigarro ao futebol:

$\mathrm{O}$ vício em futebol funciona da mesma maneira e, em alguns sentidos, meu vício no Cambridge United na época foi o mais puro que já experimentei.

\footnotetext{
${ }^{23}$ Cabe lembrar que o jogo valia a classificação para as semifinais da Copa e a partida estava empatada em 1 a 1 . O lance da penalidade máxima, cometido por Suárez, aconteceu já nos acréscimos e a disputa foi para os pênaltis, tendo o Uruguai se classificado.
}

Fumar me dá nicotina, e com isso algum estímulo e relaxamento; meu vício no Arsenal é, ocasionalmente, recompensado por copas e campeonatos [...]. Meu vício ao terrível lado de Cambridge em 1983/84 não me levou a lugar nenhum (HORNBY, 2013, s/p). ${ }^{24} 25$

O escritor retoma a veia dramática, recorrente em sua autobiografia, mas para se referir ao Cambridge United e não exatamente ao Arsenal. Apesar de que, em Febre de Bola, o Arsenal é em grande parte do tempo um time capaz de perder jogos para equipes da terceira divisão. Ao passo que aqui, embora se refira ao espaço temporal próximo ao da primeira obra, o time londrino é o que retribui seu vício, com títulos em campeonatos; sendo o Cambridge United um terrível erro de julgamento.

O texto Return of the Red Devils, também publicado no jornal The Guardian (25 jan. 1993, p. 22), é sobre o Manchester United. A chamada, no periódico, diz o seguinte: "Manchester United, o gigante caído do futebol, tem sido uma das melhores e mais duradouras piadas dos torcedores rivais. Mas quem está rindo agora?"26.

Nick Hornby, como um bom Gunner ${ }^{27}$, satiriza: "Eu expresso a fervorosa esperança de que eles vão explodir novamente, de preferência o mais tarde possível, o último minuto do último jogo da temporada, para doer mais"28 (HORNBY, 25 jan. 1993, p. 22). O Manchester United estava prestes a vencer o campeonato, mas Hornby torcendo para que não acontecesse, sob a justificativa de que o Manchester se autoconsidera o maior, melhor e mais importante clube da Europa, o que torna mais prazeroso torcer contra a equipe. Para além das alfinetadas, Hornby ameniza a situação, alegando que os torcedores contemporâneos a ele teriam, em partes, um amor pelo clube, a partir

\footnotetext{
${ }^{24}$ Originalmente: "Football addiction works in much the same way, and in some senses my addiction to Cambridge United that season was the purest I have ever experienced. Smoking gives me nicotine, and with it some stimulation and relaxation; my addiction to Arsenal is, occasionally, rewarded by cups and championships [...]. My addiction to the appalling Cambridge side of 1983/84 brought me nothing at all" (HORNBY, 2013, s/p).

${ }^{25}$ De acordo com o dispositivo Kindle, com letra tamanho 6, tal citação se encontra na posição 126 a 131 .

${ }^{26}$ Originalmente: "Manchester United, the fallen giants of football, have long been one of rival fans' best and most enduring jokes. But who's laughing now?" (HORNBY, 25 jan. 1993, p. 22).

${ }^{27}$ Torcedor do Arsenal.

${ }^{28}$ Originalmente: “I express the fervent hope that they'll blow it again, preferably as late as possible, the last minute of the last game of the season, so that it hurts more" (HORNBY, 25 jan. 1993, p. 22).
} 
de uma fixação formativa com o Manchester, que tinha os melhores jogadores.

O final dos anos 1960 e início dos 70 eram uma Era de Ouro para o futebol, tal como eram para a música pop: Best e Marsh, Dylan e Aretha, os Charlton e os Stones, Matt Busby e Berry Gordy. (Na minha adolescência, descobri que, durante o sono, confundi o pop e o futebol, os dois pilares das minhas horas acordado: costumava ter sonhos de que Rod Stewart ou Jimmy Page haviam sido "transferidos" para uma banda rival e, portanto, eu não seria mais capaz de gostar deles). Com efeito, o Manchester United era os Beatles (George Best era frequentemente chamado de "o quinto Beatle") - o maior, o melhor, o sine qua non do futebol inglês (HORNBY, 25 jan. 1993, p. 22). ${ }^{29}$

Ao exaltar o time do Manchester United como um time de celebridade, especialmente, ao fazer referência aos Beatles, parece justificar o motivo pelo qual é agradável torcer contra a equipe. Inclusive, esta é uma lógica, via de regra, dominante no futebol: a tendência em torcer contra os times mais fortes - isso nos jogos com equipes neutras, pois sempre se torcerá contra os principais rivais.

A respeito dos jogadores, continua... "[...] Eu amei o Arsenal, mas no fundo eu sabia que meus deuses - George Armstrong, John Radford, Bobby Gould não viviam na mesma montanha que Best, Law e Charlton. Bobby Gould era certamente um habitante de Scafell Pike, não do Olimpo"30 (HORNBY, 25 jan. 1993, p. 22). Nick Hornby, em um tom espirituoso, compara Sacfell Pike, a montanha mais alta da Inglaterra, com o monte Olimpo. Além daquela ser, efetivamente, mais baixa do que este, é clara a alusão ao fato de que os deuses gregos habitavam do Olimpo. Ou seja, é como se o time do Manchester estivesse ao nível da mitologia grega, ao passo que o do Arsenal

\footnotetext{
${ }^{29}$ Originalmente: "The late sixties and early seventies were a Golden age for football, just as they were for pop music: Best and Marsh, Dylan and Aretha, the Charltons and the Stones, Matt Busby and Berry Gordy. (In my adolescence I found that during sleep I confused pop and soccer, the two pillars of my waking hours: I used to have dreams that Rod Stewart or Jimmy Page had been 'transferred' to a rival band, and that therefore I would no longer be able to like them). In effect, Manchester United were the Beatles (George Best was often referred to as 'the fifth Beatle') - the biggest, the best, the sine qua non of English football" (HORNBY, 25 jan. 1993, p. 22).

${ }^{30}$ Originalmente: "[...] I loved Arsenal but deep down I knew that my gods - George Armstrong, John Radford, Bobby Gould - did not live on the same mountain as Best, Law and Charlton. Bobby Gould was surely an habitant of Scafell Pike, not Olympus" (HORNBY, 25 jan. 1993, p. 22).
}

se limitasse a uma referência geográfica, com 978 metros de altitude.

Já o time de 1993 continha apenas ecos dos anos 1960. Mesmo porque, tal como aponta Hornby, dificilmente seria possível manter jogadores do nível de Best, Law e Charlton em qualquer clube inglês, na década de 1990. Certamente, eles estariam em Turim ou Milão.

Esse texto de Nick Hornby, quando publicado pela primeira vez, em 1993, gerou repercussão entre os leitores de The Guardian. Por um lado, torcedores do Manchester United escreveram ao periódico, questionando veementemente o motivo que levou um torcedor do Arsenal a escrever sobre outro clube. O leitor Tony Smith, torcedor do Manchester United, por exemplo, respondeu à coluna de Hornby com certa indignação: “[...] Mas por que vocês deram uma página e meia do Guardian para um torcedor do Arsenal expressar sua inveja? Os assuntos do United não têm nada a ver com os torcedores do Arsenal. Qual a próxima? O Papa vai descrever o que há de errado com o Islã?" 31 (THE GUARDIAN, 27 jan. 1993, p. 17). Grande parte da irritação ficou por conta de Hornby ter escrito que o Manchester se acha o maior, melhor e mais importante clube da Europa.

Outro torcedor, Roger Brierley, comentou, também com desagrado, que um torcedor do Arsenal falando do Manchester United é tolerável; o que é inaceitável é que Hornby falasse do futuro da Premier League (THE GUARDIAN, 28 jan. 1993, p. 18).

Por outro lado, torcedores do Arsenal também se manifestaram, tanto acerca dos comentários publicados no dia 27 de janeiro, quanto à coluna de Hornby, pois não concordavam que o Manchester um dia foi o maior de todos. Os gunners Neil Finnegan e Tony Mitchell citam Tony Smith, alertando que o Manchester não é o melhor e, exatamente, por isso, aborrece a todos com sua arrogância. Michael Buckley também rebate o comentário de Smith, dizendo que este realmente falha em reconhecer que a era do Manchester United enquanto o melhor já acabou (THE GUARDIAN, 30 jan. 1993, p. 24).

Sobre a Copa do Mundo de 1994, Nick Hornby (2013), novamente fazendo as vezes de um saudosista,

\footnotetext{
${ }^{31}$ Originalmente: "[...] But why did you give an Arsenal supporter a pageand-a-half of the Guardian to express his envy? United's affairs are nothing to with Arsenal fans. What next, the Pope to write a feature on what is wrong with Islam?" (THE GUARDIAN, 27 jan. 1993, p. 17).
} 
escreve Desperately Seeking Pelé, originalmente publicado na revista Time, em 1994. Segundo o autor, a Copa precisava ser salva, especialmente se ninguém estivesse disposto a jogar futebol de verdade. Era necessário, acima de tudo, uma estrela performática, alguém capaz de atrair a atenção da mídia, já o público, principalmente o norte-americano, queria ver um espetáculo. Alguém que fizesse o que Pelé conseguiu em 1970.

Essa relativa preocupação com a competição sediada pelos EUA já dava as caras em momentos anteriores. No jornal norte-americano The Palm Beach Post, Hornby publicou um texto sobre a realização da Copa.

Queridos americanos,

Não é com frequência que escrevo para uma nação inteira [...]. No ano que vem, o seu país hospeda o Torneio de Futebol da Copa do Mundo. Na verdade, não se chama o Torneio de Futebol da Copa do Mundo; por aqui (e por "aqui”, quero dizer, em todas as outras nações da Terra), a competição é conhecida simplesmente como a Copa do Mundo (HORNBY, 12 dez. 1993, p. 14C). ${ }^{32}$

O texto é sarcástico, colocando em xeque, sobretudo, os conhecimentos futebolísticos dos norteamericanos. Hornby dá continuidade dizendo que viu um programa de TV, em que alguns norte-americanos foram perguntados sobre o que era a Copa do Mundo e foi terrível. Um deles perguntou quem ganhou, outro achou que fosse raça de cachorro e um terceiro pensou que se tratasse de sabor de sorvete.

Na sequência, o escritor explica o que é a Copa:

[...] A Copa do Mundo acontece a cada quatro anos, como as Olimpíadas - exceto pelo fato de que as pessoas realmente se importam com o que acontece na Copa. Suspeito que algumas pessoas só se importam com isso, precisamente porque sabem que nenhum americano pode vencer (HORNBY, 12 dez. 1993, p. 14C). ${ }^{33}$

\footnotetext{
${ }^{32}$ Originalmente: "Dears Americans,

It is not often that I write to an entire nation [...]. Next year, your country is hosting the World Cup Soccer Tournament. It is not really called the World Cup Soccer Tournament at all; over here (and by 'over here' I mean in every other nation on Earth) it is known simply as the World Cup (HORNBY, 12 dez. 1993, p. 14C).

${ }^{33}$ Originalmente: "[...] The World Cup happens every four years, like the Olympics - except, unlike the Olympics, people really care about what happens in it. Some people, I suspect, only care about it precisely because they know that no Americans can win the thing" (HORNBY, 12 dez. 1993, p. 14C).
}

Ao mesmo tempo em que faz piada a respeito do soccer, Hornby reconhece que os norte-americanos são dominantes no quadro de medalhas das Olimpíadas.

No sentido de que os leitores compreendessem do que falava, Nick Hornby compara a Copa de 1994, a ser sediada e "bagunçada" pelos norte-americanos a algo como se o Super Bowl fosse realizado apenas de 4 em 4 anos; e alguém tivesse a ideia de deixar a Itália sediar o evento. Hornby ainda dá dicas de como assistir ao evento e finaliza dizendo que os norte-americanos “[...] não sabem o quanto têm sorte".

Ao longo de seus escritos, Nick Hornby fala da relação forçada como um novo jogador, comparando a relações familiares ${ }^{34}$; trata da volta dos torcedores ingleses a competições europeias, apontando que estes não são mais os mesmos ${ }^{35}$; aborda a Copa de 2002 e, como sempre que a competição vem à tona, desenrola sobre a seleção brasileira e Ronaldo ${ }^{36}$; retoma, também, a seleção inglesa na Copa de 2006, reforçando que o vínculo com o Arsenal é mais forte.

Até que volta a Febre de Bola. Em Fever Pitch Revisited, posfácio para a edição da Penguin Modern Classics, de 2012, que, por sinal, é o mesmo texto da introdução comemorativa, da edição brasileira da Companhia das Letras, Hornby retoma uma série de aspectos da obra de 1992, como já comentado na presente pesquisa. Mas, cabe destacar, que o autor reconsidera alguns pontos da autobiografia, ainda que não desenrole muito sobre isso. Tal é o caso da reformulação dos estádios pós-Hillsborough. Embora o autor não fale abertamente a este respeito na autobiografia, é possível perceber dois pontos de vista. O primeiro deles se refere a uma lamentação pelo fim do Setor Norte no Highbury, que era onde a torcida entoava os cantos, que representava simbolicamente a experiência do torcer. Por outro lado, as críticas mais incisivas repousavam em relação às mudanças que vinham junto à reformulação dos estádios, que era o aumento do preço dos ingressos e a iniciativa de transformar o torcedor em consumidor - sobre o que Hornby não concordava.

Dessa forma, se em 1992, o escritor lamentava o fim do Setor Norte e se colocava ausente de

\footnotetext{
${ }^{34}$ Heroes and Villains: Perry Groves, publicado originalmente no jornal Independent, em 1992.

${ }^{35}$ A Copenhagen Jaunt, publicado originalmente na revista Loaded, em 1994. ${ }^{36}$ The 2002 World Cup, publicado originalmente na revista The New Yorker, em 2002.
} 
uma discussão mais crítica sobre os desastres que aconteceram na década de 1980; ao revisitar a obra, Hornby aponta que "[...] Depois de Hillsborough, houve um reconhecimento geral de que algo precisava ser feito - de que arquibancadas de concreto caindo aos pedaços não eram seguras, de que, no pacote de uma tarde de diversão, não deveria vir junto a ameaça de ferimento ou de morte" (HORNBY, 2013, p. 11). Finalmente, o escritor aborda as questões incisivas, possivelmente, relacionadas ao Relatório Taylor, já que, ao longo de Febre de Bola, qualquer fala com essa transparência jamais tinha se evidenciado. Ao mesmo tempo, entretanto, a assertiva de Hornby é capciosa. Há o reconhecimento de que algo deveria ser feito em relação às arquibancadas que estavam caindo aos pedaços, o que não quer dizer que ele estivesse falando de reformas em todos os estádios ingleses, com o fim das arquibancadas e inserção de cadeiras. Tal posicionamento, aparentemente pautado na ideia de reformar estádios que precisem de reforma, já havia sido manifestado no início da década de 1990, mas não em uma de suas obras.

Um dos autores que, assim como Nick Hornby, escreve sobre a experiência do torcer, é Tom Watt (1995), sobre quem será melhor tratado no capítulo seguinte. No livro The End: 80 years of life on the terraces, originalmente publicado em 1993, Watt traz depoimentos de torcedores e ex-jogadores do Arsenal, desde 1913. Parece uma iniciativa no sentido de registrar a memória de um espaço que estava prestes a deixar de existir.

Eis que um dos torcedores entrevistados por Watt foi Nick Hornby, cujas declarações são carregadas de ironia, como por exemplo, "Eu acho que mais pessoas teriam sido mortas se não tivéssemos colocado as cadeiras. Tivemos um desastre a cada 15 anos e esse não é um preço que valia a pena pagar. Preferiria me sentar do que morrer!"37 (HORNBY In WATT, 1995, p. 326). Como todo o livro é dividido por intervalos temporais, este excerto se refere ao momento entre 1987 e 1992, quando as lembranças dos entrevistados giram em torno da temática de que nada seria igual ao Setor Norte. Daí a fala de Hornby, no sentido de que, sob a sua perspectiva, não haveria motivo para que aquela arquibancada fosse reformada e paramentada

\footnotetext{
${ }^{37}$ Originalmente: “I think more people would've been killed if we hadn't gone all-seater. We had a disaster about every 15 years and that's not a price that was worth paying. I'd rather sit than die!" (HORNBY In WATT, 1995, p. 326).
}

com cadeiras. O literato, ao falar dos desastres a cada 15 anos, não se refere aos estádios ingleses, em um sentido geral; está, sim, dizendo que o Highbury é um estádio seguro, estatisticamente falando. E, para fechar, o ponto de exclamação, coroando a elegante ironia da sentença. Em se tratando de Nick Hornby, sabe-se que a pontuação não está ali por acaso especialmente tendo em vista as discussões a este respeito tanto em Febre de Bola quanto em Funny Girl (2014). Ao exclamar "Preferiria me sentar do que morrer!", Hornby deixa em dúvida se estava falando sério. Mesmo porque, naquele momento, embora reconhecesse algumas situações que poderiam ter causado sua morte ou, ainda, ele poderia ter estado em Heysel ou Hillsborough (HORNBY, 2013), o autor não se posicionava favoravelmente à colocação de cadeiras no Setor Norte.

Assim como em sua autobiografia, ao falar do período entre 1971 e 86, Nick Hornby retoma a máxima de que os torcedores, em um sentido geral, corriam perigo...

[...] Mas me lembro da minha primeira vez no Setor Norte e o Arsenal marcou e eu desci uns 15 degraus. Eu estava aterrorizado no caminho para baixo, mas era como ver as aeromoças em um avião - ninguém mais estava assustado, então pensei: isso é ótimo. E foi assim o tempo todo, de verdade, e se três ou quatro pessoas tivessem caído, você teria tido problemas. Eu acho que houve momentos em que senti que havia muitas pessoas no chão. [...]. Havia pontos que simplesmente não eram seguros - como aqueles degraus na parte de trás. Fiquei atraído por tudo isso, mas acho que, se eu soubesse o quão perigoso era, não teria me divertido tanto (HORNBY In WATT, 1995, p. 151). ${ }^{38}$

Todavia, novamente, Nick Hornby coloca um discurso duplo. Primeiramente, reconhece que a onda na arquibancada, no momento do gol, era perigosa e que todos ali corriam riscos; para logo em seguida alegar que se soubesse que aquilo era perigoso, não teria sido capaz de se divertir. Hornby satiriza a

\footnotetext{
${ }^{38}$ Originalmente: “[...] But I remember the first time I was on the North Bank and Arsenal scored and I went down about 15 steps. I was terrified on the way down but it was like watching air-stewardesses on a plane - nobody else was frightened, so I thought: this is great. And that's how it was all the time, really, and if three or four people had gone down you'd have been in trouble. I think there were times when I felt there were too many people in the ground. $[\ldots]$. There were spots that just weren't safe - like those steps at the back. I was attracted to all that but I think if I'd known how dangerous it was, I wouldn't have had quite so much fun as I did" (HORNBY In WATT, 1995, p. 151).
} 
situação e se pode hipotetizar o porquê. Como tratado anteriormente, as mortes no estádio de Heysel e em Hillsborough, apesar de uma deficiência organizativa e mesmo no espaço do estádio, não foram causadas por momentos como o descrito pelo literato. Foram catalisadas, sim, por hooligans que ou estavam perseguindo a torcida adversária ou queriam entrar no estádio sem ingresso. Dessa forma, a fala de Nick Hornby, ao ironizar um suposto apoio à reforma em Highbury, pode ser compreendida, inclusive, com um tom de indignação, já que todos os torcedores pagariam por algo que alguns indivíduos teriam causado.

Esse pensamento se coaduna ao Febre de Bola, na medida em que parece uma constante tentativa de mostrar que, talvez, a maioria dos torcedores de futebol não fossem hooligans, nem brigassem em estádios. $\mathrm{O}$ que se evidencia ao destacar, ainda na autobiografia, que pessoas que frequentam a universidade, que leem e que são bem-sucedidas frequentam o estádio. Nesse sentido, o objetivo primeiro parece ter sido uma defesa de si mesmo, enquanto torcedor. Retomando alguns dos preceitos de Philippe Lejeune (2014), ao tratar da autobiografia como um texto em que o autor mostra como se tornou o que é, não seria impossível se Febre de Bola se chamasse "Como e porque sou torcedor do Arsenal".

Sobre o comportamento dos torcedores no Setor Norte, Hornby descreve um hábito comum naquela extremidade do campo.

Havia sempre planos e coisas. As pessoas costumavam ouvir rumores, você sabe, sobre os torcedores do Rotherham ${ }^{39}$ que iriam tentar tomar o Setor Norte quando jogaram na Copa! Lembrome de um jogo quando eu era criança, uma dúzia de torcedores do Arsenal entrou cantando: Tranmere! Tranmere ${ }^{40}$ ou quem quer que fosse e o Setor Norte correu. E pensei: Ah, não! Há torcedores do Tranmere no Setor Norte. Eram apenas os torcedores do Arsenal brincando, embora houvesse uma grande fobia sobre isso, uma paranoia - que fazia parte da diversão. [...]. Mas quero dizer, havia briga dentro do Highbury, todos os sábados, entre 1968 e 75 ou 76 (HORNBY In WATT, 1995, p. 158). ${ }^{41}$

\footnotetext{
${ }^{39}$ Rotherham United Football Club que, na época, jogava a segunda divisão inglesa.

${ }^{40}$ Em referência a Tranmere Rovers Football Club.

${ }^{41}$ Originalmente: "There were always plans and things. People used to hear rumours, you know, about Rotherham supporters who were going to try and
}

Mais um exemplo de como Nick Hornby minimiza os acontecimentos, sendo difícil identificar as motivações das brigas ou mesmo a sua magnitude. Segundo aponta na autobiografia, sua estreia no Setor Norte aconteceu em 1972, quando tinha 15 anos de idade e, sobre esta que seria a sua formatura, Hornby conta que planejou com cuidado, pois estava com medo, sem saber exatamente do que (HORNBY, 2013). Quando viajava para ver jogos fora, comumente assistia ao jogo da arquibancada rival, isto é, espacialmente semelhante ao Setor Norte, porém, cheia de torcedores adversários em volta. Dessa forma, aponta que havia perigo maior do que estar entre 30 mil pessoas incentivando o Arsenal. "Depois do início assustado, comecei a amar aquele movimento, ser lançado na direção do campo e sugado de volta pro lugar" (HORNBY, 2013, p. 109). O cálculo foi que, nesta partida conta o Ipswich Town FC, dificilmente haveria invasão no Setor Norte. Escolha, ainda assim, arriscada, se pensar a declaração acima mencionada de que, neste período havia briga quase todo sábado. Mais uma vez, conta-se com o paradoxo de que, por um lado, os rumores de confusão eram uma grande brincadeira da torcida, ao mesmo tempo em que, por outro, as brigas eram frequentes.

Possivelmente, uma tentativa de minimizar as situações, até porque, mais do que incentivar o time, o Setor Norte possuía uma espécie de dever social com o clube.

Sem o Setor Norte, a tensão entre um jogador talentoso e a gerência seria quebrada anteriormente. Charlie George e Nicholas teriam saído antes George Graham não poderia se dar ao luxo de alienar a multidão em sua primeira temporada, vendendo Nicholas. Você pode ver o mesmo acontecendo com Limpar. Era muito importante que esses jogadores fossem valorizados por uma extremidade do campo (HORNBY In WATT, 1995, p. 191). ${ }^{42}$

\footnotetext{
take the North Bank when they played them in the Cup! I remember one game when I was a kid, a dozen Arsenal supporters walked in chanting: Tranmere! Tranmere! or whoever it was and the North Bank ran out. And I thought: Oh no! there's Tranmere supporters in the North Bank. That was just Arsenal supporters messing about but there was a big phobia about it, a paranoia and it was part of the fun. [...]. But I mean, there was a fight inside Highbury every single Saturday I went between about 68 and 75 or 76 " (HORNBY In WATT, 1995, p. 158).

${ }^{42}$ Originalmente: "Without the North bank, the tension between a talented player and the management would be broken earlier. Charlie George would have left sooner, Nicholas would've [sic] - George Graham couldn't afford to alienate the crowd in his first season by dropping or selling Nicholas. You can see the same thing happening with Limpar. It was very important for
} 
Trata-se de um apoio evidenciado pelos cânticos no campo, o que não significa que houvesse diálogo entre torcida e dirigentes, como inclusive, foi proposto no Relatório Taylor. E é aí que mora o ponto de grande parte da problemática, tendo em vista que Hornby apontava para uma empreitada do clube, que estaria buscando levar ao estádio um público diferente. Daí a importância, para o clube, de acabar com o Setor Norte.

Se o objetivo dos clubes é trazer um público diferente, então o público que eles querem trazer são os connoisseurs ${ }^{43}$. O problema é que apenas cerca de duas vezes por temporada você sente vontade de aplaudir qualquer coisa que aconteça no campo de futebol de ambos os lados. É por isso que não vai funcionar - o partidarismo é absolutamente o ponto do futebol. Não pode funcionar de outra maneira. [...] é simplesmente ridículo esperar que um connoisseur seja atraído por algo assim (HORNBY In WATT, 1995 , p. 267). ${ }^{44}$

Nick Hornby destaca, repetidamente, a inviabilidade de transformar o torcedor de futebol em consumidor. Tal ideia esboça certa proximidade à Febre de Bola, o que fica bastante evidente em alguns textos publicados em The Independent, inclusive, por parte do próprio jornal que, apresenta Nick Hornby como o autor daquela autobiografia. A maioria das publicações do escritor neste periódico está entre os anos de 1993 e 1995, sendo pouquíssimas delas sobre futebol - até porque a coluna escrita por Hornby fazia parte do caderno cultural, o que cria até certa polêmica por parte de alguns leitores, pois o futebol não estava restrito ao caderno esportivo. Optou-se por destacar dois dos textos de Nick Hornby, ambos referentes ao Arsenal.

Em "O que o meu eu mais jovem diria se me encontrasse agora?" (What would my younger self

\footnotetext{
those players to be valued by one end of the ground" (HORNBY In WATT, 1995, p. 191).

${ }^{43}$ Palavra francesa que indica alguém com grande conhecimento nas artes finas, cozinha e sabores. Optou-se por manter a palavra, visto que não há, no Português, uma palavra equivalente.

${ }^{44}$ Originalmente: "If the aim of the clubs is to bring in a different audience, then the audience they want to bring is the connoisseurs. The trouble is that only about twice a season that you feel like applauding anything that happens on the football pitch from either side. That's why it won't work - the partisanship is absolutely the point of football. It can't work any other way. [...] it's just ludicrous to expect the connoisseur to be attracted to anything like that" (HORNBY In WATT, 1995, p. 267)
}

say if he met me now?), Hornby fala da boa fase do Arsenal.

Eu acho que qualquer versão mais jovem de mim teria sido intimidada pelo meu desejo aparentemente inesgotável de descontentamento. Se o "eu" de 28 anos de idade, o vintage de 1985, me visse há alguns meses, vaiando o time após uma triste derrota em casa para o Bolton, ele não ficaria surpreso; o Arsenal foi terrível em 1985, e continuou por anos, então o que ele poderia esperar de diferente? (HORNBY, 11 jun. 1994, s/p). ${ }^{45}$

Sob tal devaneio, o Hornby jovem teria sido simpático às vaias, até descobrir que o Arsenal havia vencido cinco troféus nos últimos oito anos. Primeiro, ele cairia da cadeira e, depois de assimilada a ideia, jamais vaiaria a equipe. Uma lógica bastante plausível de pensamento, tendo em vista que o personagem narrado na autobiografia nunca havia visto o Arsenal vencer qualquer título. É curiosa essa abordagem ao estilo de De volta para o futuro, pois, embora o Nick do passado tenha se transformado no Nick do presente, aquele nada mais é do que a representação de um self possivel na autobiografia (LEJEUNE, 2014). Muito embora, tanto em Febre de Bola quanto na coluna do Independent, todos os Nick Hornby's apresentam um desejo inesgotável de descontentamento, tornando, portanto, possível que Nick do passado e Nick do futuro vaiassem juntos o Arsenal apático daqueles dias de 1995.

Em "Uma semana quando o futebol ficou louco" ( $A$ week when football went mad), Nick Hornby volta a abordar a temática das reformas dos estádios e o quanto isso afetou o barulho dos campos de futebol. "Os recentes redesenvolvimentos em Old Trafford, Highbury e Anfield, por exemplo, têm resultado na lamentação dos torcedores daqueles times pela falta de atmosfera nos jogos em casa" ${ }^{46}$ (HORNBY, 05 fev. 1995, s/p). A falta de atmosfera se refere à ausência do Setor Norte, em Highbury, por exemplo, aquela parte da torcida que cantava e incentivava a equipe. Somado

\footnotetext{
${ }^{45}$ Originalmente: "I think that any younger version of myself would have been daunted by my apparently inexhaustible appetite for discontent. If the 28 -yearold me, the 1985 vintage, had seen me at Arsenal a few months back, booing the team off the pitch after a dismal Cup defeat at home to Bolton, he wouldn't have been surprised; Arsenal were terrible in 1985, and had been for years, so why should he have expected any different?" (HORNBY, 11 jun. 1994, s/p). ${ }^{46}$ Originalmente: "The recent redevelopments at Old Trafford, Highbury and Anfield, for instance, have resulted in supporters of those teams bemoaning the lack of atmosphere at home games" (HORNBY, 05 fev. 1995, s/p).
} 
às transmissões dos jogos pela ITV, os estádios ficavam mais vazios e, portanto, mais silenciosos. Para Hornby, essa atmosfera se estabelece com as manifestações dos torcedores, sejam elas verbais ou gestuais, "[...] Você pula. Você acena com os braços. Você grita. Uma ou duas pessoas - oh, tudo bem, praticamente todos - usam linguagem suja e abusiva. Isso, eu sempre entendi, era para o que estávamos lá"47 (HORNBY, 05 fev. 1995, s/p). Hornby trata a linguagem suja e abusiva como a externalização da paixão pelo clube, incitada no momento do jogo... "Os guardiões morais do futebol vão se arrepender disso, mas você pode não ter os dois lados: você não pode vender o jogo em sua paixão e, em seguida, expressar consternação quando as pessoas mostram alguma"48.

Hornby apresenta a deixa para criticar a espetacularização crescente do futebol, bem como a tentativa de alcançar uma torcida que fosse consumidora. Todavia, ao retomar a questão da venda do esporte, o escritor entra em um caminho perigoso, pois, ao afirmar que o torcedor vai ao campo para xingar, pode se emparelhar à justificativa recorrente ao racismo, por exemplo. Sob a máxima do "calor do jogo", não são poucos os casos em que o preconceito de raça no estádio de futebol é justificado pela emoção. É importante ressaltar que, conforme anteriormente citado, Hornby trata, já em 2011 de dois casos no futebol, destacando o uruguaio Luis Suárez, como alguém que gera dúvidas sobre si, enquanto ser humano.

\section{CONSIDERAÇÕES FINAIS}

Para Nick Hornby, transformar os torcedores de futebol em um público apreciador - ou, como trata em Febre de Bola, em consumidores - seria inviável. Em grande parte do tempo, o torcedor de futebol está descontente com o jogo a que assiste, sendo a afetividade pelo clube, o principal motivo da permanência da torcida, ainda que o clube vá de mal a pior. É como se a autobiografia e os textos daquele período fossem o hino do Arsenal escrito em prosa, já que, essencialmente, o que Nick Hornby destaca é

\footnotetext{
${ }^{47}$ Originalmente: "You jump to your feet. You wave your right arms about. You shout. One or two people - oh, all right then, everybody, just about - uses foul and abusive language. This, I had always understood, was what we were there for" (HORNBY, 05 fev. 1995, s/p).

${ }^{48}$ Originalmente: "Football's moral guardians will regret this, but you can't have it both ways: you can't sell the game on its passion, and then express dismay when people show some" (HORNBY, 05 fev. 1995, s/p).
}

que "Vencendo ou perdendo / É você que escolhemos" (Whether you win or lose / It's you that we choose).

A escrita do futebol na década de 1990 e início dos anos 2000, como verificado em Fan Mail e no próprio Febre de Bola, é diferente da escrita da década dos anos 2010, como se percebe a partir de Pray. Com base nos elementos contextuais e no quanto estes interferem no texto, é provável que essa mudança na forma de escrita seja um reflexo - entre outras coisas, como a autonomia do autor -, do esporte em si. Pois, a modalidade da década de 1990 é absolutamente distinta do modelo contemporâneo espetacularizado. Assim, é possível que essas mudanças no contexto esportivo tenham influenciado a produção de Hornby, que já não aborda os efeitos afetivos do futebol, mas estritamente o que acontece em campo.

As publicações no jornal The Independent reafirmam o que já foi mencionado anteriormente, sobre a forte presença das características e mesmo do conteúdo exposto em Febre de Bola, nos escritos dos anos 1990. Para além de todas as mudanças do esporte, é importante lembrar, também, que graças à autobiografia, Nick Hornby passou a ser colunista em alguns periódicos, nos quais escrevia também sobre futebol - ou exclusivamente sobre isso. Dessa forma, escrever sobre futebol no jornal implica tratar dos acontecimentos futebolísticos, aproximandose do formato da crônica não apenas pela forma de escrita, como pela proximidade com a notícia. Daí as diferenças na forma de escrever entre a década de 90 e os anos 2000. O saudosismo em relação ao futebol tende a aparecer nas colunas culturais, em que o futebol não é o principal assunto a ser tratado.

Dessa forma, pode-se pensar em três apresentações distintas do esporte, segundo as produções de Nick Hornby: 1) o futebol que corresponderia a um mito do passado mais feliz, atrelado aos sentimentos do escritor e, portanto, eivado de subjetividade, presente na autobiografia, na entrevista a Tom Watt e nas colunas culturais. 2) A modalidade como ela é, paradoxalmente presente nas obras de ficção, no sentido de conferir verossimilhança aos textos, via de regra, ocupando uma passagem bastante curta da narrativa. Por fim, 3) pode-se pensar no futebol atrelado à notícia, presente nas colunas esportivas dos jornais, conferindo objetividade na forma de escrever, bem como ao próprio esporte. 


\section{REFERÊNCIAS}

ALBERTI, Verena. Literatura e Autobiografia: a questão do sujeito na narrativa. Estudos Históricos, Rio de Janeiro, v. 4, n. 7, p. 66-81, 1991.

CALADO, Eliana Alda de Freitas. Da História ou da Literatura? O Limbo das Autobiografias. Saeculum - Revista de História, João Pessoa, n. 20, p.103-110, jan./jun. 2009.

CANDIDO, Antonio. Literatura e Sociedade: estudos de Teoria e História Literária. 13 ${ }^{\mathrm{a}}$ ed. Rio de Janeiro: Ouro sobre Azul, 2014.

ESPN. Nick Hornby looks back on Arsenal's worst season in 21 years. 15 jun. 2017. Disponível em: <http://www. espn.com/soccer/club/arsenal/359/blog/post/3143118/ nick-hornby-on-arsenal-and-arsene-wenger-after-horriblepremier-league-campaign>. Acesso em: 19 dez. 2017.

GOLDBLATT, David. The Game of Our Lives - the meaning and making of English Football. Londres: Penguin Books, 2015.

HILL, Jeffrey. Sport and the Literary Imagination. Oxford/ Bern: Peter Lang, 2006.

HORNBY, Nick. Febre de Bola. São Paulo: Companhia das Letras, 2013. (Originalmente publicado em 1992).

(Org.). My favourite year: a collection of football writing. Londres: Phoenix, 2001, Kindle Edition. (Originalmente publicado em 1993).

Return of the Red Devils. Londres: The Guardian, 25 jan. 1993, p. 22.

. Don't blow this World Cup Thing. Florida: The Palm Beach Post, 12 dez. 1993, p. 14C.

What would my younger self say if he met me now? Londres: The Independent, 11 jun. 1994. Disponível em: $\quad<\mathrm{http}: / / \mathrm{www}$.independent.co.uk/artsentertainment/wh atwouldmyyoungerselfsayifhemetmenow 1421982.html>. Acesso em: 01 mar. 2017.

. A week when football went mad. Londres: The Independent, 05 fev. 1995. Disponível em: <http://www. independent.co.uk/sport/aweekfootballwentmad5420489. html>. Acesso em: 01 mar. 2017.

. Alta fidelidade. São Paulo: Companhia das Letras, 2013. (Originalmente publicado em 1995).

Como Ser Legal. Rio de Janeiro: Rocco, 2002. (Originalmente publicado em 2001).

31 Canções. Rio de Janeiro: Rocco, 2005. (Originalmente publicado em 2003).

. Uma Longa Queda. São Paulo: Companhia das Letras, 2014. (Originalmente, publicado em 2005).
Pray: Notes on the 2011/2012 Football Season. Londres: Penguin Specials, 2012, Kindle Edition.

.Fan Mail: twenty years of writing about soccer. Londres: Penguin Specials, 2013, Kindle Edition.

Pequeno País. In: Vários autores. Foras da lei barulhentos, bolhas raivosas e algumas outras. São Paulo: Cosac Naify, 2012. p. 15-38.

. Funny Girl. Londres: Penguin Books, 2014.

KING, Anthony. The end of terraces: the transformation of English football em the 1990s. Londres: Leicester University Press, 2002. (Originalmente publicado em 1998).

LEJEUNE, Philippe. O pacto autobiográfico: de Rousseau à internet. Belo Horizonte: Editora UFMG, 2014.

LISE, Natasha Santos. Arsenal, we're on your side: uma análise do futebol em Nick Hornby. Curitiba: Departamento de Educação Física da Universidade Federal do Paraná (Tese de Doutorado), 2018. 189 p.

SANTOS, Márcia Pereira dos. A compreensão do si mesmo e do outro em autobiografias: contribuições ricoeurianas na escrita da história. Goiás: Emblemas - Revista do Departamento de História e Ciências Sociais, v. 1, n. 2, 2006.

THE GUARDIAN. Hot Shots. Londres: The Guardian, 27 jan. 1993, p. 17.

1993, p. 18

Team Spirit. Londres: The Guardian, 28 jan. jan. 1993, p. 24.

Sick as parrots. Londres: The Guardian, 30

TYLER, Anne. Almoço no Restaurante da Saudade. São Paulo: Mandarim, 1998.

WATT, Tom. The End - 80 years of life on the terraces. Edimburgo: Mainstream Publishing, 1995. (Originalmente publicado em 1993).

WROE, Martin. 'Soccerati' out of closet. Londres: The Observer, 31 out. 1993, p. 6.

YOUTUBE. Nick Hornby: "Funny Girl" Google Talks. 10 fev. 2015. Disponível em: <https:/www.youtube.com/ watch?v=S0Vo2-1KC8s>. Acesso em: 18 dez. 2017.

. The BAFTA \& BFI Screenwriters' Lecture Series - Nick Hornby. 30 set. 2016. Disponível em: <https:// www.youtube.com $/$ watch? $\mathrm{v}=\mathrm{vmzdBSsgboM}>$. Acesso em: 06 dez. 2017. 